\title{
A three year experience in Laparoscopic Appendectomy
}

\author{
Sharon $\mathbf{W}^{1}$ \\ ${ }^{1}$ Dr. Wormi Sharon, Assistant Professor, Department of General Surgery, Jawaharlal Nehru Institute of Medical \\ Sciences, Porompat, Imphal, India.
}

Corresponding Author: Dr. Wormi Sharon, Email: wormi2008@gmail.com

\begin{abstract}
Background: Acute appendicitis is one of the most common causes of acute abdomen. It may occur from the time of infancy to old age, but the peak age of incidence is in the second and third decades of life. The lifetime risk of appendicitis is approximately $7-8 \%$. Today in developed countries, about $8 \%$ of the population is treated for acute appendicitis in the course of their lifetime. The outcome can be very serious at both extremes of life and there is a life time risk of developing acute appendicitis in about 5-8\%. The aim of this study was to evaluate the clinical results of laparoscopic appendectomy (LA) for the treatment of acute appendicitis. Material and Methods: A retrospective analysis fall patients who underwent laparoscopic appendectomy diagnosed with acute appendicitis overa3yearperiodwasreviewed. Data were retrieved from our departmental data base and analyzed using descriptive statistics. Most of the patients were diagnosed to have appendicitis by ultrasound or have ruled out other cause of right lower abdominal pain especially in females. Results: Out of the 226 patients who underwent laparoscopic appendectomy, $138(61.1 \%)$ were females and the remaining $88(38.9 \%)$ were males. Most of them are in the age group of 21-40years. 171 (75.7\%) patients were discharged within 48 hours. Conclusion: Laparoscopic appendectomy is as safe and effective as conventional surgery, has a higher diagnostic yield, causes less trauma, and offers a more rapid postoperative recovery. Such features make laparoscopy a challenging alternative to laparotomy in premenopausal women referred for urgent abdominal or pelvic surgery, or both.
\end{abstract}

Keywords- Acute appendicitis, Laparoscopic Appendectomy (LA), Open Appendectomy (OA)

\section{Introduction}

Appendicitis is one of the most common acute abdomen conditions requiring surgery, with a lifetime incidence of $6-8 \%$. Appendectomy has long been the gold standard of treatment due to its efficacy and low mortality. Laparoscopic appendectomy (LA), initially described by Semm in 1983 has increasingly gained favor in the past decade in management of selected cases of acute appendicitis [1].

The benefit of LA as a minimal access surgery include less post-operative pain, shorter hospital stay, early return to work and better cosmesis[2,3]. These benefits have made this approach attractive. Despite all these benefits, LA has not been wildly accepted as a standard of care for management of all cases. This is due to dispute regarding its advantage compared with open surgery. Perforated appendicitis may be seen in $20-30 \%$ of patients with acute appendicitis [4]. Perforation is

Manuscript Received: $20^{\text {th }}$ January 2018

Reviewed: $28^{\text {th }}$ January 2018

Author Corrected: $4^{\text {th }}$ February 2018

Accepted for Publication: $9^{\text {th }}$ February 2018 associated with a high risk of postoperative complications, including wound infection and intraabdominal abscess. Laparos-copic appende-ctomy (LA) has become a common intervention worldwide in recent years. The use of laparoscopic appendectomy for complicated appendicitis is controversial, especially with regard to the rate of postoperative infectious complications including wound infection and abscess formation in abdominal cavity $[5,6]$.

Laparoscopy has emerged as the standard surgical approach to a wide host of diseases of the upper abdomen, but its role in the management algorithm of lower abdominal emergencies awaits definite clarification.

This is especially true for suspected appendicitis, a disease of huge epidemiological impact and several diagnostic challenges $[7,8]$. The purpose of this study is to evaluate the outcome of laparoscopic appendectomy for the treatment of acute appendicitis. 


\section{Material and Method}

A retrospective analysis of patients who had undergone laparoscopic appendectomy for acute appendicitis between $1^{\text {st }}$ January 2013 and $31^{\text {st }}$ December 2016 has been performed. This data is taken only from one surgical unit (unit 4) in the department of General Surgery, JNIMS, Imphal. Only the data of those patients who have undergone laparoscopic appendectomy were taken. The diagnosis of acute appendicitis was established with physical examination, laboratory tests and ultrasound examination or has ruled out other cause of right lower abdominal pain especially in females. All the procedure was performed by Laparoscopic surgeon.

The operation is performed under general anesthesia. The bladder is usually emptied by asking the patient tourinate immediately prior to the procedure. The techniques were similar to those described in the laparoscopic literature. LA was usually performed with the patients in a Trendelenburg position rotated right side up and a three-trocar technique at the umbilical, suprapubic, and right lower quadrant positions. The surgeons altered trocar placement at their discretion. Using a 30" video laparoscope the mesoappendix was segmentally ligated or thermo coagulated to the base, the appendix was doubly ligated with 1-0 vicryl, and the stump was not buried. An end pouch was used to retrieve the specimen more frequently. All the patients received pre-operative antibiotic continued post operatively as indicated.
Statistical Methods-Descriptive and inferential statistical analysis has been carried out in the present study. Results on continuous measurements are presented on Mean \pm SD (Min-Max) and results on categorical measurements are presented in Number (\%). Significance is assessed at $5 \%$ level of significance. The following assumptions on data is made,

Assumptions: 1. Dependent variables should be normally distributed, 2.Samples drawn from the population should be random, Cases of the samples should be independent

Chi-square/ Fisher Exact test has been used to find the significance of study parameters on categorical scale between two or more groups, Non-parametric setting for Qualitative data analysis.

Significant figures

+ Suggestive significance ( $\mathrm{P}$ value: $0.05<\mathrm{P}<0.10$ )

* Moderately significant ( $\mathrm{P}$ value: $0.01<\mathrm{P} \leq 0.05$ )

** Strongly significant $(\mathrm{P}$ value: $\mathrm{P} \leq 0.01)$

Statistical software: The Statistical software namely SPSS 18.0, and R environment ver.3.2.2 were used for the analysis of the data and Microsoft word and Excel have been used to generate graphs, tables etc.

\section{Results}

A total of 226 patients underwent Laparoscopic Appendectomy.Most of the patients are in the age group of 21-40 years (42.5\%) followed by 41-60 (29.2\%) years age group.

Table-1: Age distribution of patients studied.

\begin{tabular}{|c|c|c|}
\hline Age in years & No. of patients & \% \\
\hline $1-20$ & 38 & 16.8 \\
\hline $21-40$ & 96 & 42.5 \\
\hline $41-60$ & 66 & 29.2 \\
\hline $61-80$ & 23 & 10.2 \\
\hline$>80$ & 3 & 1.3 \\
\hline Total & $\mathbf{2 2 6}$ & $\mathbf{1 0 0 . 0}$ \\
\hline
\end{tabular}

Mean \pm SD: $38.61 \pm 17.32$

Table-2: Gender distribution of patients studied.

\begin{tabular}{|c|c|c|}
\hline Gender & No. of patients & \% \\
\hline Female & 138 & 61.1 \\
\hline Male & 88 & 38.9 \\
\hline Total & $\mathbf{2 2 6}$ & $\mathbf{1 0 0 . 0}$ \\
\hline
\end{tabular}

In this study, Female patients were found to be more compared to males. 
Table-3: Hospital Stay.

\begin{tabular}{|c|c|c|}
\hline No. of days in hospital & No. of patients & \% \\
\hline $1-2$ & 171 & 65.7 \\
\hline $3-4$ & 15 & 15.9 \\
\hline $5-6$ & 36 & 1.8 \\
\hline 7 or more & 4 & $\mathbf{1 0 0 . 0}$ \\
\hline Total & $\mathbf{2 2 6}$ & \\
\hline
\end{tabular}

Mean \pm SD: $2.77 \pm 1.88$

Majority of the patients got discharged within 48 hours.

Table-4: Drain distribution of patients studied.

\begin{tabular}{|c|c|c|}
\hline Drain & No. of patients & \% \\
\hline No & 194 & 85.8 \\
\hline Yes & 32 & 14.2 \\
\hline Total & $\mathbf{2 2 6}$ & $\mathbf{1 0 0 . 0}$ \\
\hline
\end{tabular}

In this study out of 226 patients, 32 patients had drain (table 4 ).

Table-5: No. of days in hospital distribution of patients studied in relation to Drain

\begin{tabular}{|c|c|c|c|}
\hline \multirow{2}{*}{ No. of days in hospital } & \multicolumn{2}{|c|}{ Drain } & \multirow{2}{*}{ Total } \\
\cline { 2 - 3 } & No & Yes & $171(75.7 \%)$ \\
\hline $1-2$ & $171(88.1 \%)$ & $0(0 \%)$ & $15(6.6 \%)$ \\
\hline $3-4$ & $11(5.7 \%)$ & $4(12.5 \%)$ & $36(15.9 \%)$ \\
\hline $5-6$ & $9(4.6 \%)$ & $27(84.4 \%)$ & $4(1.8 \%)$ \\
\hline 7 or more & $3(1.5 \%)$ & $1(3.1 \%)$ & $\mathbf{2 2 6}(\mathbf{1 0 0} \%)$ \\
\hline Total & $\mathbf{1 9 4}(\mathbf{1 0 0} \%)$ & $\mathbf{3 2}(\mathbf{1 0 0} \%)$ & \\
\hline
\end{tabular}

$\mathrm{P}<0.001^{* *}$, significant, Chi-Square test

The decision to put drain was taken during the time of surgery. Also the duration of their stay in hospital goes up for the patients with drain as shown in table 5 .

\section{Discussion}

The open appendectomythrough right grid iron incision was introduced by Mc Burney (Mc Burney 1894) and thistechnique enjoyed decades of un-opposed reputation and widespread use globally becauseof its proven safety and efficacy. The introduction of laparoscopy has brought a majorchange in the field of surgery. The laparoscopic appendectomy is gradually gainingpopularity over the past $10-15$ years by way of proving improved diagnostic outcome anddecreased rate of wound problems. It was way back in 1983 when a first laparoscopicsurgery for acute appendicitis was performed by a German Gynaecologist Semm (Semm K1983) [1]. LA has all the potential benefits of other minimal access procedures; many studies having demonstrated lower complication rates, shorter hospitalization, and more rapid recovery and return to normal activity[3].
Laparoscopy has gained widespread acceptance in common surgical practice as a diagnostic and therapeutictool [9]. Suspected appendicitis is still a diagnostic challenge to the general surgeon. To plan the appropriate procedure or to avoid an unnecessary laparotomy, a correct diagnosis is crucial because of the various diseases that may be responsible for the same symptoms. Noninvasive diagnostic procedures are expensive and not always conclusive [10].

Laparoscopy is the only minimally invasive technique that allows concurrently an appropriate diagnosis and treatment and the best abdominal approach. It is generally believed that minimally invasive surgeries result in less post-operative pain, fewer complication rates and shorter recovery periods in comparison to open procedures [11]. Initially with the introduction of 


\section{Original Research Article}

laparoscopy in surgery, reports on the use of laparoscopy for appendicitis focused only on its efficacy as a diagnostic tool. The advantage of LA over open procedure was supported by several studies [12, 13]. For instance, a meta-analysis has shown that LA results in earlier resumption of normal activity, less post-operative complications and longer operative time [14]. Nowzaradan et al., that laparoscopic appendectomy resulted in less post-operative pain, shorter hospitalization and earlier returns to normal activities [15]. In many studies, LA has been attributed with a relatively low incidence of complications compared with OA [16]. In this study too, there were no major complications at post-operative period, only those patients with drain stays for a longer period in Hospital.

Drain was place intra-operatively in view of intraoperative finding like perforated appendix, gangrenous or with fluid/ abscess collection.

A particular problem with laparoscopic appendectomy is the differing experience of surgeons performing this operating procedure. Several studies proved that appendectomy is an ideal operation for the introduction of general surgery trainees in laparoscopic surgery [16, 17].

Things might be more difficult in complicated cases. But, as surgical expertise increases with the number of operations, a surgeon who routinely performs appendectomy laparoscopically will more likely be able to handle complicated appendectomies in the same manner. The diagnostic accuracy of laparoscopy is very high, $89 \%$ to $100 \%$ rate reported in the international literature $[8,9]$.

The high diagnostic yield of laparoscopy is even greater if we consider all the concomitant diseases we found in patients without histology proven appendicitis. In agreement with other authors, we always remove the appendix, even when it appears macroscopically normal [18].

Debate still exists about the cost comparisons between laparoscopic and open appendectomy. Most surgeons have the opinion that laparoscopic appendectomy is cost effective. It may be more expensive for the hospital but it offers diagnostic accuracy, offerscost saving to society as a result of faster returns to work [19].

\section{Conclusion}

Laparoscopic appendectomy is as safe and effective as conventional surgery, has a higher diagnostic yield, causes less trauma, and offers a more rapid postoperative recovery. Such features make laparoscopy a challenging alternative to laparotomy in premenopausal women referred for urgent abdominal or pelvic surgery, or both.

Sparing unnecessary laparotomies, reduces postoperative pain, increases prompt recovery of gastrointestinal functions, shorten hospitalization, helps contain healthcare costs, and increases cosmesis. On these grounds, we advocate wider adoption of laparoscopy and are confident it will become more important in common surgical practice.

Conflict of interest: None declared.

Funding: Nil, Permission from IRB: Yes

\section{References}

1. Ekeh AP, Wozniak CJ, Monson B, Crawford J, McCarthy MC. Laparoscopy in the contemporary management of acute appendicitis. Am J Surg. 2007 Mar; 193 (3):310-3; discussion 313-4.

2. Garbutt JM, Soper NJ, Shannon WD, Botero A, Littenberg B. Meta-analysis of randomized controlled trialscomparing laparoscopic and open appendectomy. Surg Laparosc Endosc. 1999 Jan;9(1):17-26.

3. Golub R, Siddiqui F, Pohl D. Laparoscopic versus open appendectomy: a metaanalysis. J Am Coll Surg. 1998 May; 186(5):545-53.

4. Andersson RE, Hugander A, Thulin AJ. Diagnostic accuracy and perforation rate in appendicitis: association with age and sex of the patient and with appendicectomy rate. Eur J Surg. 1992 Jan;158(1):3741.

5. Katkhouda N, Friedlander MH, Grant SW, Achanta KK, Essani R, Paik P, Velmahos G, Campos G, Mason $\mathrm{R}$, Mavor E. Intraabdominal abscess rate after laparoscopic appendectomy. Am J Surg. 2000 Dec; 180 (6): 456-9; discussion 460-1.

6. So JB, Chiong EC, Chiong E, Cheah WK, Lomanto D, Goh P, Kum CK. Laparoscopic appendectomy for perforated appendicitis. December 2002, Volume 26, Issue 12, pp 1485-1488

7. Chung RS, Rowland DY, Li P, Diaz J. A metaanalysis of randomized controlled trials of laparoscopic versus conventional appendectomy. Am J Surg. 1999 Mar;177 (3): 250-6. 


\section{Original Research Article}

8. Nguyen DB, Silen W, Hodin RA. Appendectomy in the pre- and postlaparoscopic eras. J Gastrointest Surg. 1999 Jan-Feb;3(1):67-73.

9. Heinzelmann M, Schob O, Gianom D, Platz A, Simmen HP. Role of laparoscopy in the management of acute appendicitis. Zetralbl Chir. 1999; 124 (12):1130-1136.

10. Shaikh AR, Sangrasi AK, Shaikh GA. Clinical outcomes of laparoscopic versus open appendectomy. JSLS. 2009 Oct-Dec; 13 (4): 574-80. doi: 10. 4293/ 10868 0809X1258998404524.

11. Peters JH, Ellison EC, Innes JT, Liss JL, Nichols KE, Lomano JM, etal. Safety and efficacy of laparoscopic cholecystectomy. A prospective analysis of 100 initial patients. Ann Surg 1991; 213: 3-12.

12. Schirmer BD, Edge SB, Dix J, Hyser MJ, Hanks JB, Jones RS. Laparoscopic cholecystectomy. Treatment of choice for symptomatic cholelithiasis. Ann Surg. 1991 Jun; 213 (6): 665-76; discussion 677.

13. Sauerland S, Lefering R, Holthausen U, Neugebauer EA. Laparoscopic vsconventional appendectomy--a meta-analysis of randomised controlled trials. Langen becks Arch Surg. 1998 Aug; 383 (3-4): 289-95.
14. Frazee RC, Roberts JW, Symmonds RE, Snyder SK, Hendricks JC, Smith RW, et al. A prospective randomized trial comparing open versus laparoscopic appendectomy. Ann Surg 1994; 219: 725-8.

15. Rashid A, Nazir S, Kakroo SM, Chalkoo MA, Razvi SA, Wani AA. Laparoscopic interval appendectomy versus open interval appendectomy: a prospective randomized controlled trial. Surg Laparosc Endosc Percutan Tech. 2013 Feb; 23 (1):93-6. doi: 10.1097/SLE. 0b013e318277df6a.

16. Tata MD, Singh R, Bakar AA, Selvindoss P, P K, Gurunathan R. Laparoscopic appendicectomy: the ideal procedure for laparoscopic skill training for surgical registrars. Asian J Surg. 2008 Apr;31(2):55-8.

17. Duff SE, Dixon AR: Laparoscopic appendicectomy: safe and useful for training. Ann R Coll Surg Engl; 2000; 82 (6):388-91.

18. Lau WY, Fan ST, Yiu TF, Chu KW, Suen HC, Wong KK. The clinical significance of routine histo pathologic study of the resectedappendix and safety of appendicealinversion. Surg Gynecol Obstet. 1986 Mar;162(3):256-8.

19. Cuschieri A. Cost efficacy of laparos copicvs open surgery. Hospitals vs community. Surg Endosc. 1998 Oct; 12 (10):1197-8.

\section{How to cite this article?}

Sharon W. A three year experience in Laparoscopic Appendectomy. Surgical Update:Int J surg Orthopedics.2018; 4(1): 01-05. doi:10.17511/ijoso.2018.i01.01. 